\title{
Kernos
}

Revue internationale et pluridisciplinaire de religion grecque antique

$23 \mid 2010$

Varia

\section{Paolo SCARPI (éd.), La Rivelazione segreta di Ermete Trismegisto}

\section{André Motte}

\section{OpenEdition \\ Journals}

\section{Édition électronique}

URL : http://journals.openedition.org/kernos/1659

DOI : 10.4000/kernos. 1659

ISSN : 2034-7871

\section{Éditeur}

Centre international d'étude de la religion grecque antique

\section{Édition imprimée}

Date de publication : 1 janvier 2010

Pagination : 406-407

ISSN : 0776-3824

\section{Référence électronique}

André Motte, « Paolo scarpI (éd.), La Rivelazione segreta di Ermete Trismegisto », Kernos [En ligne], 23 | 2010, mis en ligne le 15 septembre 2011, consulté le 21 septembre 2020. URL : http:// journals.openedition.org/kernos/1659; DOI : https://doi.org/10.4000/kernos.1659

Ce document a été généré automatiquement le 21 septembre 2020.

Kernos 


\title{
Paolo SCARPI (éd.), La Rivelazione segreta di Ermete Trismegisto
}

\author{
André Motte
}

\section{RÉFÉRENCE}

Paolo SCARPI (éd.), La Rivelazione segreta di Ermete Trismegisto. Vol. 1, Milano, Fondazione Lorenzo Valla/Arnoldo Mondadori Editore, 2009. 1 vol. $13 \times 20,5 \mathrm{~cm}, 543$ p. (Scrittori Greci e Latini). ISBN : 978-88-04-58352-3.

1 Le zèle que l'A. met en œuvre pour diffuser des collections de textes anciens qui sont des passages obligés pour l'étude de la religion grecque est décidément inépuisable. Après avoir publié, avec l'appui déjà de la Fondation L. Valla, I miti greci du pseudoApollodore, en 1996, puis, en deux copieux volumes, Le religioni dei misteri en 2002 (voir Kernos 16 [2003], p. 365-366), il s'attaque à présent à l'hermétisme. Voici le premier des deux volumes annoncés.

Ouvre l'ouvrage, après la table des matières, une ample et substantielle introduction (p. XI-XCIII) qui commence par évoquer l'étonnante postérité qu'ont connu, depuis l'Antiquité jusqu'à nos jours, les écrits hermétiques, tant chez des penseurs comme Marsile Ficin, qui les a traduits avant même de s'occuper de Platon, que chez des poètes comme Dante et des artistes comme Jérôme Bosch et Pierre Breugel. Viennent ensuite un exposé des recherches historiques et philologiques qui leur ont été consacrées (et qu'a enrichies la découverte de nouveaux textes, en 1945, à Nag Hammadi), un aperçu des manuscrits conservés, une chronologie des textes hermétiques dont la production s'étale du début de notre ère jusqu'au moyen âge, une brève carte de visite d'Hermès "Trois fois grand » (dieu grec assimilé, comme on sait, à l'égyptien Thot qui préside à l'écriture, à l'astrologie et à l'alchimie), une présentation des principales doctrines concernées (théologie, cosmologie, anthropologie, eschatologie) et aussi des éléments cultuels véhiculés. Loin s'en faut qu'on ait affaire à un enseignement uniforme et 
cohérent, même si l'idée d'une connaissance révélée y forme un dénominateur commun. Suit une bibliographie de près de 250 titres.

Ce premier volume comprend trois ensembles distincts de textes d'une ampleur fort inégale et faisant chacun l'objet d'une brève caractérisation et d'une introduction de portée philologique. Le premier, qui ne compte qu'une dizaine de pages, est fait d'un catéchisme de "définitions " attribuées à Hermès et dont n'existe qu'une version en arménien. L'édition de référence est celle de J.-P Mahé (1982), mais n'apparaît ici que la traduction italienne, due à Igor Dorfmann-Lazarev, auteur aussi des notes. À défaut du texte arménien, le traducteur a ajouté un lexique d'une cinquantaine de mots italiens accompagnés des mots arméniens qu'ils traduisent et, le cas échéant, d'un équivalent grec. Le deuxième ensemble, de beaucoup le plus volumineux (p. 25-251) est formé des 18 traités, philosophiques et théosophiques, traditionnellement désignés sous le nom de Corpus hermeticum. Au regard de la traduction italienne, on dispose ici du texte grec (sans apparat critique), qui suit l'édition fameuse de A.D. Nock et d'A.-J. Festugière aux Belles Lettres (1945-1954). Cinq auteurs se sont partagé la traduction : Ch. Cremonesi, L. Savignago, A. Rodighiero, M. Zago et P. Scarpi, qui traduit notamment le célèbre traité I, le Poimandrès, et est également l'auteur de toutes les notes. Sous l'étiquette de "Manuel pédagogique» que lui donne l'éditeur, le troisième ensemble (p. 253-389) réunit 29 textes hermétiques tirés de l'Anthologie de Stobée et traitant de sujets variés. Trois traducteurs ont ici pris la relève: $\mathrm{S}$. Feraboli, Ch. Poltronieri et A. Tessier; les notes sont à nouveau l'œuvre de P.S. et sont rejetées, comme pour les deux ensembles précédents, à la fin de l'ouvrage (l'ensemble des notes couvrent les pages 391-543). Dans le volume II, dont le contenu est annoncé, on trouvera notamment l'Hermès latin, avec le célèbre Asclépius, traité conservé dans une adaptation latine attribuée à Apulée.

Nul doute que cette édition ne rende de précieux services par la solide mise au point qu'offre l'introduction et par les notes érudites, sans parler de la traduction que je n'ai pas qualité pour juger.

\section{AUTEURS}

\section{ANDRÉ MOTTE}

Université de Liège 